\title{
PENSAR UMA ANTROPOLOGIA DAS PROFUNDEZAS À LUZ DE QUESTÕES DA EPISTEMOLOGIA GENÉTICA ${ }^{1}$
}

\author{
Ana Luiza Carvalho da Rocha
}

\section{Introdução}

Inicialmente gostaria de agradecer o convite que me foi feito para participar deste encontro, pois enquanto antropóloga, trabalhando há sete anos no GEEMPA com o processo de escolarização de alunos de classes populares de Porto Alegre, encontro aqui uma chance de interlocução com pesquisadores e intelectuais de outras áreas preocupados com o tema das aprendizagens humanas.

Minha participação neste encontro constituir-se-á de uma reflexão em torno dos comentários de J. Piaget acerca da natureza social da mente humana no sentido de cotejá-la com as produções recentes da sociologia das profundezas, em particular, com a tradição de pensamento inaugurada pelos estudos de G. Durand sobre as estruturas antropológicas do imaginário.

Inicialmente cabe ressaltar que minha intenção aqui é trazer algumas reações de estudos da Antropologia do imaginário às abordagens da epistemologia genética quanto ao fenômeno das diferenças das formas de pensamento geradas no interior das sociedades humanas. Em particular, refiro-me aos estudos piagetianos a respeito do aparecimento do fenômeno da existência de representações coletivas racionais no bojo da vida social.

Neste sentido, tenho claro que minhas observações vão traduzir inquietações particulares que nutrem meu projeto intelectual e existencial situado nas interfaces entre os estudos do imaginário e as contribuições da ecologia cognitiva. Em especial, meus comentários partem de uma preocupação epistemológica que me é cara: não negligenciar as contribuições da etnologia e da mitologia à filosofia do conhecimento ao apontarem a tendência da épistémè ocidental moderna, tributária da tradição judaicocristã, em degradar o lugar da imaginação nas formas de produção do conhecimento humano a partir de sua adesão, até certo ponto, irrestrita à soberba das estruturas racionais produzidas no campo das categorias científicas como as únicas possíveis de

\footnotetext{
${ }^{1}$ Palestra proferida no I Seminário Entrelaçando discursos da Ciência. Universidade Católica de Pelotas, Pelotas/RS, 1996.
} 
trazerem os homens à humanidade.

Já há algum tempo, J. Piaget alertava para as "degeneracões sucessivas ao culto subjetivo da ambigüidade ou do irracional" 2 que se faziam presentes nos estudos sociológicos inspirados numa fenomenologia husserliana e em sua tentativa de explicar as categorias do pensamento humano e suas normas enfocando-as como meros produtos sociais, frutos do processo de formação de novas gerações e sua integração na sociedade como fenômeno histórico, deixando ao esquecimento o seu processo genético.

Apontando para a debilidade de tal orientação filosófica nos estudos das categorias de entendimento humanas, o autor sugeria diferir, no corpo de uma fenomenologia do sujeito social, níveis hierárquicos na estruturação do espírito, individual e coletivo ${ }^{\mathfrak{B}}$, vistos segundo sua universalidade, sua profundidade e seus modos de construção genéticos.

Em relação às correntes dialéticas, J. Piaget comentava o abandono do diálogo entre a Sociologia e as disciplinas que se ocupam do desenvolvimento genético ou histórico do conhecimento humano. As correntes dialéticas apresentariam uma fragilidade epistemológica ao relegar ao esquecimento o sentido dinâmico e construtivista das superações contínuas na forma como o conhecimento humano se processou ao longo da história das sociedades, fruto de uma seqüência de desequilíbrios, crises e de reequilibrações progressivas da vida social.

Sugeria, esse autor, o relativismo como método de investigação ao propagar a tese central que afirma ser a construção do conhecimento humano um fenômeno solidário das interações sujeito e objeto (tese da fenomenologia) que se configurava numa dupla direção: "de uma exteriorização objetivante" do sujeito e de uma "interiorização reflexiva" do real (tese central da dialética).

Retomarei aqui este tema à luz do processo de polimorfismo das estruturas cognitivas presentes no trajeto antropológico de conformação do sujeito humano e da pesquisa dos signos e dos símbolos culturais, das regras e dos valores sociais que configuram a experiência da vida coletiva.

Ao propor, nos moldes de uma epistemologia genética, a complementaridade das correntes filosóficas da fenomenologia e da dialética, J. Piaget alertava, de forma original, para o fato de que o conhecimento científico não germina no vazio de significações, ao contrário cresce e adquire vigor no solo fértil das representações

\footnotetext{
${ }^{2}$ Cf. Jean Piaget, Estudos Sociológicos. Barcelona, Ariel SA, 1983, p. 9.

${ }^{3}$ op.cit., p. 11.
} 
coletivas que inundam a vida social e, por isso mesmo, nutre-se de tais representações para formular e conceber o universo da ciência.

As condições possíveis de os dados da consciência atingirem a explicação causal das aprendizagens humanas a partir do campo da ciência dependeriam, portanto, da possibilidade que existe para as Ciências Sociais de reverter a contaminação que sofre das representações coletivas e atingir um grau de compreensão "objetiva" das ações executadas pelos sujeitos sociais.

\section{Orientações antropológicas que subjazem uma epistemologia genética}

Apontando para o fato de a vida social constituir-se, portanto, como um dos fatores essenciais da formação e da ampliação dos conhecimentos pré-científicos em conceitos científicos, Piaget vai, progressivamente, afirmar a importância de se sobrepor os estudos das estruturas orgânicas e das estruturas sociais na forma como se configura a produção do conhecimento humano.

A contribuição que traz aqui J. Piaget é pertinente à matriz disciplinar da Antropologia uma vez que avança ao afirmar que existem estruturas orgânicas e instintivas que subjazem às produções culturais humanas estando estas subordinadas aos sistemas de valores e regras de caráter coletivo e ao observar que o desenvolvimento das formas de conhecimento no homem são dependentes tanto de uma maturação orgânica do indivíduo quanto da evolução da vida social. O construtivismo reflexivo conclui, assim, a favor de um sistema de interdependência das explicações sociológicas e biológicas acerca da formação da razão humana.

Nos termos piagetianos, a aquisição da linguagem pelo homem supõe, "além da assimilação de uma língua já organizada", um "sistema de signos coletivos que se transmitem de geração a geração através da educação" que, por sua vez, pauta-se numa “condição biológica prévia (e peculiar à espécie humana) que é a sua capacidade de aprender uma linguagem articulada".

Por outro lado, impossível de se pensar a formação da razão humana sem se observar as interdependências das explicações sociológicas e psicológicas. De acordo com J. Piaget, entre as estruturas sociais e as estruturas psicológicas não existem "vínculos de superposição ou de sucessão hierárquico" como nas anteriores (explicações biológica e sociológica), senão "vínculos de coordenação e, até mesmo, de interpretação".

Em termos antropológicos poder-se-ia dizer que o filhote humano não recebe, 
portanto, meramente noções coletivas através das quais opera com o real, mas elege entre as representações ambientes aqueles elementos que são assimiláveis segundo leis precisas de sucessão operatórias psicogenéticas, ligadas precisamente à vida de sua espécie.

\section{Estudos etnológicos sob a ótica da epistemologia genética}

São os estudos clássicos da Antropologia (funcional e estruturalista) a respeito das representações coletivas (Durkheim) ${ }^{4}$ das categorias de pensamento primitivas (Lévy-Bruhl) ${ }^{5}$ e acerca do pensamento selvagem (Lévi-Strauss) ${ }^{6}$ que J. Piaget irá percorrer para tecer uma sociopsicogênese das operações lógicas e da vida social do homem da civilização. Explorando a tradição intelectualista francesa e a explicação que traz seu paradigma racionalista em Antropologia, Piaget tece algumas importantes observações acerca da formação sócio-psicológica dos conhecimentos científicos e de sua evolução histórica, Segundo o autor, o próprio objeto de investigação das Ciências Sociais engloba conhecimentos coletivos uma vez que o racionalismo francês privilegiando a consciência - e uma consciência racional - nos seus estudos acerca das categorias do entendimento humano constrói a diferença das operações lógicas e racionais da ciência com as quais o homem da civilização opera o entendimento do mundo das categorias de entendimento mágicas e religiosas dos povos ditos primitivos.

Visto sob o ângulo de uma perspectiva sociopsicogenética, tanto o pensamento sociológico elaborado por Durkheim, em fins do séc. XIX, como os sistemas teleológicos de sociedades tribais os quais eram o centro de interesse da Escola Sociológica Francesa, "falam", em níveis distintos de hierarquia, dos aspectos indissociáveis de toda a formação do real que experienciou a espécie humana ao longo de sua evolução e maturação.

Com isso a epistemologia genética de J.Piaget propõe uma original via de estudo das formas de conhecimento humano para a Antropologia ao estabelecer uma analogia entre a formação das noções da criança civilizada no curso de sua socialização com as operações com o real e aquelas realizadas pelo homo sapiens até tornar-se sapiens.

Oferece, assim, um campo fértil de pesquisa ao correlacionar, numa perspectiva

\footnotetext{
4 Cf. E. Durkhem, "Représentation individuelles et représentations collectives", in: Revue de Métaphysique e de Morale (1898) e Les formes élèmentaires de la vie religieuss. Alcan, Paris, 1912; além da obra conjunta com M. Mauss, Les formes primitives de classification, in Année sociologique, VI. Paris, 1901-1902.

${ }_{5}^{5}$ Cf. L. Lévy-Bruhl, La mentalité primitive, Alcan, Paris, 1925.

${ }^{6}$ Cf. C.Levi-Strauss, La pensée sauvage, Plon, Paris, 1962.
} 
filogenética, a formação das noções científicas e filosóficas que se sucedem na história do pensamento das civilizações humanas rumo a suas estruturas superiores com o trajeto desconstrução das operações complexas superiores vivido pela criança segundo o processo de maturação de suas estruturas cognitivas.

Nesse novo contexto de abordagem do processo sociopsicogenético das formas do conhecimento humano, a maturação do pensamento humano até atingir o estágio de idéias científicas, como foi o caso das mutações ocorridas nas noções de tempo e espaço de Galileu a Descartes, significou uma mutação intelectual nas sociedades humanas, num paralelismo (que não é termo a termo) com o processo e desenvolvimento de uma inteligência sensório-motora na criança até esta atingir as operações lógico-abstratas acerca do mundo ${ }^{7}$.

O abandono do pensamento figurativo ou intuitivo representou para a espécie humana não uma pura e simples substituição de idéias antigas por novas acerca do homem e do mundo. Ao contrário, tal fenômeno significou para a história do homo sapiens sapiens um longo processo de maturação sociopsicogenético das sociedades humanas cujas etapas seguem sendo relativamente constantes em sua ordem de sucessão.

O homem da civilização desponta, portanto, no quadro da evolução de sua espécie como parte integrante de processos de equilibração da própria vida social. No interior dessa seqüência temporal encontra-se um processo dialético que vai da mutação das estruturas de conhecimento humano de formas elementares às formas superiores do pensamento (esquemas sensório-motores, juízos intuitivos e juízos lógicos), da maturação dos arranjos da vida social em formas coercitivas às formas mais cooperativas, onde desponta finalmente o tema complexo da socialização da inteligência individual $^{8}$.

Associa-se ao caráter egocêntrico dos intercâmbios sociais presentes em sociedades tradicionais o caráter figurativo e intuitivo do pensamento humano

\footnotetext{
${ }^{7}$ Vigotsky, op. cit, p. 12, observa que Piaget admite que mesmo "a atividade lógica não é tudo o que existe para a inteligência", e que, sob uma "longa e persistente pressão social". Há uma transição entre a lógica dos sonhos (egocêntrica) e a lógica dos pensamentos. O pensamento sincrético que representa tal transição para muitos etnológos baseia-se em estruturas sintéticas do imaginário, regido pelo princípio de participação. Aos outros dois corresponderiam às estruturas místicas (sob o princípio de correspondência ou analogia) e estruturas esquizomorfas (sob o princípio de ruptura), respectivamente.

${ }^{8}$ Como Piaget, Vigostky, Pensamento e Linguagem, Martins Fontes, SP, 1995, desenvolve a idéia de uma interdependência funcional psíquica para o desenvolvimento da consciência na criança, entretanto atribui a linguagem (uso dos signos) mais que do que a ação como lugar de mediação simbólica que orienta, na criança, a passagem de estruturas pré-intelectuais para as funções psicológicas mais complexas (lógicas e analíticas).
} 
"primitivo" ou "arcaico" que, por diferenças hierárquicas das operações lógicas baseadas em trocas sociais descentradas e cooperativas criadas do homem da civilização, impõe limites à socialização de categorias coletivas racionais à inteligência individual.

Entretanto, o pensamento figurativo ou intuitivo, marca registrada das sociedades tradicionais e que tão bem pontuou a etnologia funcionalista e estruturalista, "livre do egocentrismo dos esquemas sensório-motores" que subjazem às representações coletivas, traz em si a potencialidade das operações lógicas propriamente ditas uma vez que ações executadas mentalmente (através de ações imaginadas, como no caso da magia) se exercem sobre a representação das coisas (a representação aqui evoca, por meio dos símbolos, as ações concretas com o real servindo de "significantes" a realidades "significadas").

Portanto, o despontar das operações lógicas e racionais no horizonte do conhecimento humano está atrelado, em vários graus, à passagem da ação efetiva e irreversível da inteligência individual sobre o real às formas de operação ou ação virtual e reversível com o mundo das formas sociais ${ }^{9}$.

\section{Inteligência individual e operações lógicas sob a ótica da etnologia}

Segundo a epistemologia genética, portanto, o pensamento pré-lógico presente às sociedades tradicionais investigadas pelos antropólogos tem suas origens nos constrangimentos sociais que asseguram a permanência no corpo das representações coletivas de uma mentalidade similar à egocêntrica infantil, impedindo por tais artifícios aos membros dessas sociedades uma "maturação" em direção a mecanismos operatórios que definem a razão humana.

A "mentalidade primitiva" apontada pela Escola Sociológica Francesa é, nos termos piagetianos, tributária de formas e arranjos da vida social onde as relações interpessoais dos indivíduos são afetadas por constrangimentos exteriores ao sujeito. Em tais sociedades, o valor atribuído à autoridade e à submissão conduz seus membros a sobrevalorizar o traço "subjetivo" nas formas como a sociedade se organiza enquanto corpo de crenças e verdades imóveis e irreversíveis (leia-se aqui a

\footnotetext{
${ }^{9}$ Cf. Vigotsky, op. cit. p. 17, o pensamento de natureza egocêntrica (que "emerge quando a criança transfere formas sociais e cooperativas do comportamento para a esfera das funções psíquicas interiores e pessoais") cumpre um papel importante na estruturação das funções psicológicas superiores no homem pois representa uma transição entre a fala oral e a fala interior, reflexiva e consciente, servindo tanto o pensamento autista quanto ao lógico.
} 
pessoalidade/localismo de normas e regras onde se encontram ausentes aspectos universais da lógica formal).

Por outro lado, se em nossas sociedades civilizadas o espírito lógico sobrepõe-se à "pré-lógica" da mentalidade primitiva, é porque nesse contexto vigora uma estrutura intelectual diferente nas formas de arranjo da vida social, ou seja, o fator cooperativo (leia-se impessoal) de nossas inter-relações sociais.

Retomando a clássica definição durkheimiana de solidariedade orgânica e mecânica, pode-se dizer que o fator de objetividade/impessoalidade que funda as sociedades civilizadas como sociedades cooperativas produz, gera e amadurece um tipo de inteligência individual no sujeito humano capaz de fazê-lo atingir a maturidade de operações lógicas de conhecimento. Nesse contexto, as ações humanas no mundo têm por base uma cosmovisão onde os arranjos da vida social são suscetíveis de serem "agrupados" por meio de operações racionais. ${ }^{10}$

Dito de forma mais precisa, na análise das diferenças hierárquicas de estruturas de pensamento e formas de conhecimento (magia, religião, ciência), J. Piaget acaba por estabelecer uma analogia entre os processos que orientam as inter-relações entre a lógica individual e a lógica social tomando como ponto de partida os esquemas de equilibração e sobrevalorização dos ritmos da vida social na forma como o indivíduo opera com a consciência, em especial, a consciência racional. Assim, uma crença estará melhor assegurada "se ela faz parte de um sistema coerente e não se choca com nenhuma crença contraditória".

Dessa forma, a preeminência das representações coletivas racionais no mundo civilizado ou das representações mágicas e religiosas nas sociedades "primitivas" e “arcaicas" dependem da sobrevalorização ou não da verdade de ordem operatória da inteligência individual que conduz à acumulação de espécies de "capitais de crenças", que são as religiões, os sistemas morais e jurídicos, as ideologias políticas, etc. Sob a ótica da preeminência de uma consciência racional como fator que caracteriza a humanidade no homem, nos termos piagetianos, dir-se-ia que a "equilibração" que se estabelece entre a inteligência individual e a vida coletiva tendem a superação dos conflitos por eliminação de opiniões similares ou heresias.

Nesses termos, as sociedades terminam sempre por subordinar, em níveis

\footnotetext{
${ }^{10}$ Cf. Vigotsky, op. cit, p. 19, Piaget tendo separado a necessidade e o prazer da adaptação à realidade, "é forçado pela lógica a apresentar o pensamento realista como algo dissociado das necessidades, interesses e desejos concretos, como 'pensamento puro', cuja única função é à busca da verdade pela verdade”.
} 
distintos de hierarquia, a lógica individual à social, seja nos termos das sociedades primitivas, teocracias, seja o inverso, no caso das modernas sociedades democráticas. De onde a máxima piagetiana: "Noções teleológicas para a lógica social ou noções de espaço-tempo objetivas para a lógica individual" ${ }^{11}$.

\section{Sociopsicogênese dos processos mentais revista à luz das evidências antropológicas}

$\mathrm{Na}$ perspectiva pós-piagetiana de uma sociopsicogênese dos processos mentais humanos poder-se-ia ir além da análise sociológica do pensamento filosófico em função dos diversos tipos sociais de diferenciação do conhecimento humano, segundo as nações e classes da sociedade.

Tal perspectiva está anunciada na obra de J. Piaget, Estudos Sociológicos, mas se interrompe no momento exato em que o autor analisa o despontar do humanismo universalizante do Ocidente do séc. XIX e XX, oriundo das filosofias sociais do séc. XVII e XVIII. Tomando esse período da história do pensamento filosófico para suas reflexões, e abdicando de enfocar o problema a partir dos achados da arqueologia e da pré-história acerca do sistema de signos e de imagens que configuram a grande aventura da humanidade, Piaget aponta para um grau de mutação na história do pensamento ocidental onde se pretendia substituir explicações teleológicas da origem das sociedades humanas por uma explicação fundada na natureza e nas atitudes naturais dos homens (egocentrismo). ${ }^{12}$

Semelhante processo de maturação nas formas de conhecimento construídas pelo homem da civilização pode ser localizado no período da Ilustração, momento singular onde vão se fundar alguns dos postulados da ciência moderna tais quais se conhece hoje. Na época, debatia-se entre duas vias de compreensão do mundo social: por um lado, conceber uma natureza humana anterior as relações sociais ou, por outro lado, enfocar as instituições sociais como fenômenos derivados das intenções e das vontades individuais.

Nesse primeiro estágio de formulação das representações coletivas racionais, solo fértil onde irá crescer o pensamento científico, inverte-se a ordem das causas e dos efeitos na forma como se processa o entendimento das relações entre homem e mundo:

\footnotetext{
${ }^{11}$ Cf. J. Piaget, op. cit., p. 172.

12 Alain Tourraine em sua obra, Crítica da Modernidade, Vozes, Petrópolis, 1995, explora de forma contundente o "antihumanismo" destes séculos que deram origem ao nascimento do sujeito, período em que legisladores, filósofos e intelectuais contribuíram para a crença triunfante de que a ciência, com suas operações mentais superiores (lógicas e racionais) ocuparia posição privilegiada na forma o homem e da civilização observa, classifica e ordena a vida social.
} 
a sociedade aparece como resultado da socialização dos indivíduos e a consciência individual torna-se atributo de uma conjunto de faculdades acabadas, sob a forma de um espírito humano dado a priori.

Para sair deste impasse de um espírito à priori que reina soberano sobre as formas de arranjo da vida social onde o indivíduo se sente presa da armadilha da "natureza humana", no processo de equilibração entre inteligência individual e vida coletiva, o pensamento social da época vai construir operações mentais mais complexas acerca do mundo social ao observar a experiência concreta das instituições sociais a partir da máxima de um sóciomorfismo: "é necessário explicar o homem pela humanidade e não a humanidade pelo homem".

Deriva-se deste processo sociopsicogenético das representações racionais no Ocidente moderno, portanto, o sociocentrismo da idéia de que certas formas de pensamento são o reflexo das preocupações coletivas do grupo a que pertencem, chegando a radicalidade da afirmação de que "não é a consciência do homem que determina sua forma de ser, senão sua forma de ser social que determina sua consciência".

Neste sentido, o pensamento individual é interpretado como mero reflexo da cosmovisão do grupo ao qual pertence, graças a linguagem e as pressões das gerações, sendo o indivíduo tributário de aquisições anteriores, transmitidas via a "educação". Aqui no caso, as regras lógicas de pensamento são socialmente determinadas e superam os limites da atividade individual, supondo a colaboração dos espíritos, superior e anterior as consciências individuais.

Instaura-se aí, a pretensão dos estudos científicos no campo das ciências sociais de reconstruir a história do espírito humano que reside no interior da "consciência coletiva", num esquema de pensamento que corre o perigo de enfocar a "consciência coletiva" como a nova herdeira dos poderes inatos a priori do espírito ou, nas palavras de J.Piaget como "lugar inconsciente das emanações conscientes".

\section{O logos racional e as formas superiores de equilibração da vida social}

Da investigação acerca das operações lógicas de conhecimento como formas superiores complexas de equilibração da vida social, as quais são tributárias da "maturação" das formas de vida coletiva, apresentada pela epistemologia genética o que se depreende para os estudos das representações coletivas racionais é que elas categorias são interdependentes da formação histórico-psico-social do campo das ditas ciências 
sociais.

A importância da análise das operações lógicas que regem as relações entre inteligência individual e vida social, numa perspectiva sóciopsicogenética da formação dos conceitos científicos das Ciências Sociais, recai no estudo dos problemas epistemológicos que derivam do aparecimento da categoria sociológica do "nós" empregada pelo pesquisador nos seus estudos sobre as sociedades humanas.

Muito se tem dito, hoje, acerca da particularidade do campo disciplinar das Ciências Sociais, onde o observador geralmente faz parte da "totalidade que estuda ou de uma totalidade análoga ou adversa" ${ }^{13}$. No entanto, J. Piaget foi um precursor do "relativismo" nas Ciências Sociais ao precisar que nesta área de conhecimento (mais do que em Psicologia) "um considerável conjunto de "pré-noções, sentimentos postulados implícitos (morais, jurídicos, políticos, etc.) e de preconceitos de classe se interpõe entre o sujeito e seu objeto de investigação," e onde a "descentração do primeiro é condição de toda a objetividade científica", sendo "infinitamente mais difícil que em outras partes" 14 .

Disto resultou o predomínio de uma sociologia da consciência tanto na análise do social quanto do indivíduo, esquecendo-se que, nos moldes de uma epistemologia genética, o sujeito social é sede de um pensamento e procede por ações coletivas cujas interações elementares consistem de ações que modificam umas às outras de acordo com leis de equilibração. As explicações na ordem das representações coletivas (sejam elas racionais ou não) abarcam, portanto, a compreensão particular das interações que se processam no interior dos comportamentos sociais humanos. ${ }^{15}$

Ligando as formas do pensamento humano (representações coletivas) às ações sociais e individuais sobre o mundo (condutas executadas), Piaget estabelece um vínculo sociopsicogenético entre o pensamento egocêntrico arcaico que rege a vida das sociedades humanas em sua feição primitiva e as formas de pensamento científicas universalistas, como o caso do pensamento científico, que o autor associa ao pensamento descentrado e objetivo. ${ }^{16}$

Poder-se-ia dizer que no seu esforço para legitimar-se como conhecimento

\footnotetext{
13 op. cit. p. 22

14 ibidem

15 Mereceria aqui cotejar algumas das observações de Piaget com outras obras de natureza filosófica como as de M. Foucault, Arqueologia do saber e As palavras e as Coisas, e de T. S. Kuhn, A estrutura das revoluções cientificais que permitem ampliar o quadro descrito por Piaget nos termos do conjunto de compromissos em que se baseia a prática cientifica.

${ }^{16}$ Ver a respeito a obra de A. Léroi-Gouhran, Evolução e Técnicas, vol. I e II, Edições 70, s.d.
} 
científico, as categorias de entendimento produzidas pelas ciências sociais tendem a afastar-se de um pensamento egocêntrico e subjetivo que impregna o horizonte das representações coletivas (senso comum), acompanhando um trajeto de "maturação" de estruturas sociais humanas para, finalmente, realizar-se como campo disciplinar.

Disto decorrem algumas inferências importantes. Primeiro, depreende-se a idéia de a "descentração do sujeito" é condição sine qua non para a maturação do pensamento científico que as modernas sociedades civilizadas vieram a gerar e produzir. Segundo que tal "descentração" é condição da objetividade e da capacidade heurística das categorias empregadas pelas ciências sociais para compreender e explicar o mundo, constituindo o conhecimento científico uma modalidade de conhecimento reversível e, assim, reflexivo, que difere do pensamento figurativo ou intuitivo (selvagem) que impregna as ditas sociedades tradicionais onde a Ciência não vingou.

Estudos da pré-história acerca do semantismo dos símbolos que fundam as técnicas humanas (para além de uma filogenese) reforçam as contribuições da epsitemologia genética ao mostrar que o sujeito e objeto do conhecimento humano não aparecem como forças bipolares e opostas nas origens do homo-sapiens, mas encontram-se unificados segundo princípios diretores homólogos que os reúne numa unidade monadológica. Da mesma forma, estudos da história das religiões e da mitologia esclarecem que a organização dualista homem-mundo se processa com os fundamentos da lógica aristotélica que a ciência positivista herdou do Ocidente judeu cristão. ${ }^{17}$

Tal afirmação se amplia se enfocarmos os estudos de Leroi-Gourhan, Goody, Havelock e Lafont a propósito do pensamento simbólico que preside a formação da linguagem humana, de signos figurativos à escrita. ${ }^{18}$ Eis aí onde os trabalhos de uma sociologia das profundezas, em particular os estudos de G. Durand ${ }^{19}$ sobre as estruturas antropológicas do imaginário contribuem para re-fundar, a partir de outra tradição disciplinar, algumas das contribuições da epistemologia genética acerca da vida social

\footnotetext{
17 Novamente, cf. Vigotsky, op. cit.. p. 2l, e em auxílio de inúmeros estudos etnológicos, Piaget "considera que o homem primitivo aprende a partir da experiência apenas em alguns poucos casos especiais e limitados de atividade prática- e cita a agricultura, a caça, a manufatura de objetos como exemplos de casos raros", ignorando que agricultura e caça não são contatos humanos desprezíveis com a realidade, pois estas atividades constituem toda a sua existência".

${ }_{18}$ A propósito ver A. Leroi-Gouhran, La Geste et la Parole, Albin Michel, Paris, 1968. Goody, J. La Raison graphique: la doméstication de la pensée sauvage, Minuit, Paris, 1979 e La logique de l'écriture: aux origines de la société humaine, Armand Colin, Paris, 1981, e, ainda, Havelock, E. Aux origines de la civilisation de l'écrite en Occident. Maspero, Paris, 1981 e Lafont, R. Anthrotopologie de l'écriture. CCI Centre George Pompidou, 1984.

${ }^{19}$ Cf. G. Durand, Les structures anthropologiques de l'imginaire, Dunod, Paris, 1984.
} 
na elaboração das operações lógicas no sujeito humano.

\section{Sociologia das profundezas, inteligência individual e o semantismo dos símbolos sociais}

Retornando ao tema do egocentrismo das sociedades "primitivas" e "arcaicas" oposto as estruturas lógicas das operações do conhecimento pautadas pelo sociocentrismo das ditas sociedades civilizadas, as representações coletivas racionais vão pouco à pouco consolidar a idéia de que, pelo relativismo que lhe é inerente, o pensamento científico representou uma ruptura de segunda ordem com as representações coletivas das sociedades tradicionais.

Como isto procederia? Invocando, com a "descentração do sujeito", um sóciomorfismo das representações coletivas, a Ciência amadurece rumo a um sóciocentrismo, correndo o risco de, ao ter por base o "egocentrismo" da civilização ocidental em sua fase de expansão colonial que visionava abarcar uma totalidade social maior - a humanidade - e, assim, desfigurar aqui a figura central do debate o Homem.

Sem dúvida, a epistemologia genética recoloca em pauta, dentro de outro paradigma de entendimento, os achados da etnologia de tradição intelectualista em Antropologia, mas acaba caindo nas armadilhas de soberba da Razão, ao postular que há povos e civilizações cuja mentalidade é pré-lógica devido aos "constrangimentos" de caráter social sobre as estruturas cognitivas do sujeito humano, esta espécie de cristalização de estruturas de pensamento "arcaicas" podem ser analisadas à luz do que hoje se encontra entre os filhotes do homem civilizado.

Contra o positivismo e o historicismo evolucionista de tais conclusões, cabe aqui se prosseguir com a tarefa iniciada por J. Piaget mesmo isto implique problematizar-se não apenas a "linha de tempo" adotada por este autor, mas sua teoria dos estágios. A partir dos achados recentes de pré-historiadores, mitólogos e etnólogos reinvindica-se aqui um estudo mais detalhado do percurso da civilização ocidental que afastou o conhecimento do conhecimento produzido pela Ciência de uma visão filosófica de homem que "precede a toda a história e a todo o discurso" ${ }^{20}$, seja ele científico, místico ou religioso. ${ }^{21}$

\footnotetext{
${ }^{20}$ Cf. G. Durand, Science de l'homme e tradition, Berg. Internacional, Paris, 1979.

21 Seguindo a afirmação de T. S. Khun, op. cit., p.24, que "a ciência normal, ..., é baseada no pressuposto de que a comunidade científica sabe como é o mundo", nada poderia nos garantir, como supunha Piaget, que a as operações lógicas com as quais opera o homem da civilização estejam tão afastadas, como queria Durkherim, de sistemas de crenças tanto quanto não exprimiriam sistemas de
} 
As contribuições da epistemologica genética devem fazer avançar, na tentativa de se compreender o trajeto antropológico do homo sapiens sapiens, uma crítica aguçada ao cartesianismo da epistemologia ocidental moderna em sua tentativa de impor um monopólio metodológico de conhecimento do real que afastou progressivamente a possibilidade de conceber a imaginação criadora no processo de construção das operações mentais com as quais o homem opera com o mundo, criando um fosso entre o homem arcaico e o civilizado.

$\mathrm{Na}$ busca de "um novo espírito antropológico", e ampliando o conceitual piagetiano acerca do sociocentrismo das ditas ciências sociais, é necessário que se revisite a sóciopsicogênese das categorias científicas a ponto de incluir neste horizonte a démarche histórica e dessacralizante através da qual a filosofia do Ocidente judeut cristão retirou o homem da metafísica, da moral e da religião para, finalmente, realocálo no corpo da "naturalização" sociopolítica das representações coletivas racionais.

A luz das contribuições de G. Dúmezil, de C. Lévi-Strauss, de G. Durand, de R. Caillois, de R. Guénon, de Mircea Eliade, E. Cassirer, P. Ricoeur e outros tantos que comentam as origens do homem da civilização, trata-se de apontar para a estrutura mitológica das explicações das ditas ciências do homem, rompendo com a parcialização de suas produções teórico-conceituais que geram a idéia errônea de que a construção do conhecimento humano enquanto fruto dos seus atos conscientes e racionais é o destino total da humanidade.

Para dar unidade a figura do homem, a sociologia das profundezas re-coloca o tema do conhecimento humano e das categorias de entendimento para além dos cantões das "explicações" lingüísticas, sociológicas e psicológicas que enfocam o pensamento humano como mera resposta objetiva a traumatismos psíquicos ou sociais ou negam o não-causalismo objetivo que anima as interelações entre a inteligência humana e os processos de vida coletiva, numa tentativa de ultrapassar até certo ponto a rigidez da teoria dos estágios presentes ao pensamento piagetiano.

Considerando uma sequiência temporal, e longe de proceder por analogia que estabelece relações formais, em geral, funcionais, entre o indivíduo humano e a vida social, o que se coloca aos homens da ciência é a aceitação de que o conhecimento científico deve proceder a compreensão arqueológica das interelações entre a

constrangimentos no plano das trocas sociais. Como nos coloca novamente T.S. Kuhn: “... a ciência normal freqüentemente suprime novidades fundamentais, porque estas subvertem necessariamente seus compromissos básicos", idem. 
inteligência humana e os processos de vida coletiva, partindo de suas homologias e jogando com a materialidade de elementos similares da obras humanas (linguagem, arte, religião, ciência) que a etnologia clássica e contemporânea oferece.

De forma mais radical, torna-se necessário se acentuar a crítica à visão piagetina da formação histórica dos conceitos científicos para, logo após, se retornar a ela na tentativa de observar como as operações lógicas que o homem da civilização veicula trazem o germe da crise da ciência na contemporaneidade uma vez que rompe com a idéia tradicional do homem como não-dualidade lógica, caindo ora no racionalismo exacerbado, ora no irracionalismo decadente.

O que hoje deve ser ponderado pelas ciências humanas é fato de que o conhecimento humano, em sua pluralidade, segue todo um outro percurso que não o da causalidade finalista e fatalista da formulação de ordens complexas de estruturação do conhecimento. Ou seja, todo conhecimento humano (linguagem, arte, religião, ciência) obedece a uma hermenêutica interior na qual o pensamento toma forma, segundo uma progressão psicológica, calcada em modelos de graus de conhecimento de tipo iniciático. $^{22}$

Cabe aqui se ressaltar que antes de ser um animal racional, o homem é um animal simbólico, sendo o símbolo constitutivo da consciência, ao mesmo tempo indireto e concreto, elemento decisivo de equilibração biológica e psico-social do ser humano, tal qual nos revelou J. Piaget em várias de suas obras.

De acordo com tais formulações, todo o conhecimento (mesmo o científico) é o conhecimento transcendente de uma totalidade m qual cada coisa se situa em relação à unidade do conjunto, numa rede de correspondências e similitudes simbólicas cuja causalidade não se reduz a conexões de coisas a séries infinitas e simples. Assim, é a função simbólica essencialmente função eufêmica do pensamento humano cujo dinamismo prospectivo tende a organizar suas formas de conhecimento do e no mundo, e a subsidiar até mesmo as operações lógico-formais.

Advogar uma posição contraria a redução do mundo a abstração das categorias mentais que supõe uma oposição dualista entre um sujeito e um objeto, onde, para os, racionalistas, o Cogito é a única sede de um conhecimento universal e intercambiável e,

\footnotetext{
22 Não se está longe de aproximar tais comentários de G. Durand dos de Vigotsky quando ele afirma a propósito da fala humana ser o significado um ato de pensamento no sentido pleno do termo, uma vez que o caracter comunicacional do pensamento humano significa que ele reflete uma realidade conceitualizada. Em termos durandianos poder-se-ia dizer que o trajeto que vai da fala interiorizada as formas mais complexas do pensamento humano é dependente da socialização escolar, uma espécie de "modelo iniciático" onde o filhote humano é assimilado e acomoda-se a uma civilização da escrita.
} 
para os empiristas, o homem torna-se tabula rasa recebendo as qualidades sensíveis do mundo exterior, é permanecer no campo da investigação criado pela própria epistemologia genética.. Entretanto, não sacrificar o conhecimento humano ao postulado da integração do Cogito e de suas operações lógicas, é romper com as amarras do "sociocentrismo" da civilização ocidental, branca, judaico-cristã que ameaça o conhecimento acerca do conhecimento humano. Tal pode ser verificado quando J. Piaget engendra em sua obra Estudos Sociológicos uma figura de homem desconectada do vivido (mas não do social) fazendo sobressair uma visão homogênea de sociedade humana "civilizada" que se vale hegemonicamente dos métodos intelectualistas de apreensão das coisas.

Contra o gigantesco etnocentrismo cultural (sociocentrismo, nos termos de Piaget) oriundo da cosmovisão judaicio-cristã, o que se torna desafiante é percorrer uma investigação sistemática acerca das "constantes de sentido" elaborados pelo homo sapiens ao longo da sua "maturação" biológica como homo sapiens sapiens, além das variações diferenciais que as constituem no corpo da história de um Ocidente mítico.

Como alguém interessado no estudo do simbolismo, entendo que se deva apostar não apenas na compreensão dos esquemas lógicos do pensamento humano e suas formas de "operar" com o real, mas igualmente no campo dos estudos acerca da imaginação simbólica criadora, propondo uma hermenêutica das representações das estruturas mentais humanas que seja capaz de integrar o homem arcaico e o civilizado.

Se, as produções culturais humanas são fatores de equilibração (leia-se aqui de integração social e cultural, cf. pontuado por Piaget), cabe se salientar, nas trilhas de uma sociologia de profundezas, que o equilíbrio sociohistórico da inteligência individual face à vida social nada mais é que uma "realização simbólica" do trajeto antropológico do sujeito humano em seu confronto com as "sístoles e diástoles, mais ou menos rápidas ou lentas, da vida cultural dos povos e sociedades".

Para a sociologia das profundezas e o campo de estudos da dimensão ecológica do psiquismo, a arte, a religião, o mito ou a linguagem são formas de objetivação constitutivas do real tão sólidas e vitais como aquelas elaboradas pela via científica e técnica ou pela via da "razão pura teórica" existindo uma passagem contínua entre uma e outra, não cabendo, pois aqui se insistir na controversa (como apontou Piaget para o caso dos estudos sociológicos) entre o pensamento egocêntrico (pensamento selvagem, figurativo e intuitivo) e o sociomórfico (pensamento domesticado ou científico, constituído a partir de esquemas lógicos e formais). 
Seguindo a perspectiva do homo simbolicus, ao invés do homo rationalis, é necessário se insistir no estudo das estruturas da inteligência humana como fenômeno que contém um não-causalismo objetivo. Desta forma, é importante que se admita algumas das contribuições da etnologia e da etnometodologia à epistemologia genética para que se possa reconhecer que a "a razão e a ciência só une os homem através das coisas", mas o que une realmente os homens entre si. É a representação afetiva, porque vivida, e que constitui o império das imagens" isto porque o mesmo "espírito da espécie" esta presente "tanto no pensamento 'primitivo' quanto no pensamento civilizado, no pensamento normal como no pensamento patológico".

No que diz respeito às similitudes dos ritmos sociológicos que acompanham a construção do conhecimento pelas sociedades humanas ao longo do tempo, à epistemologia genética talvez cumpra reconhecer que o pensamento humano se formula dentro de um quadro de não dualidade lógica antes de inserir-se num quadro aristotélico que se pauta pelo princípio de não contradição, e que rege o pensamento dualista do homem ocidental desde a Renascença.

$\mathrm{Na}$ perspectiva de uma arqueologia das estruturas do pensamento humano, o trajeto antropológico do homo sapiens sapiens se constrói a partir de um processo que se afasta do edifício lógico clássico, pois avança e complexifica-se estabelecendo "hierarquias" intermediárias nas vinculações homem/ mundo exterior sem perder de vista o pluralismo de formas de conhecimento e categorias de pensamento humanas e de suas vias de acesso ao real.

Talvez seja relevante se pensar aqui uma forma de se prosseguir o debate iniciado por J. Piaget e sua epistemologia genética sobre as interrrelações entre inteligência individual e representações coletivas à luz das modalidades que as produções simbólicas da cultura humana oferecem para o estudo do conhecimento da espécie homo sapiens sapiens.

A idéia é que se possa buscar a inspiração de um novo "espírito antropológico" que oriente os estudos das formas de pensamento humano baseando-se na recusa toda a ideologia filosófica oriunda das querelas escolásticas que opunha materialismo e idealismo ou espiritualismo e que se fundam numa visão do Ser oposta ao não-Ser, separando o eu e o mundo, o sujeito e o objeto do conhecimento.

Como deixa antever J. Piaget, na sua obra Estudos Sociológicos, talvez seja o momento se prosseguir no rumo da afirmação de uma ciência unificada do homem, recusando-se a uma visão fragmentada do seu trajeto antropológico e suas 
regionalidades, da qual se originou uma visão mutilada e redutora da figura do homem no corpo das representações coletivas das sociedades civilizadas.

Na perspectiva de ecumenismo científico, os dias de hoje desafiam as ciências humanas a aprofundar os estudos acerca do homem a partir de uma visão unitária tomando-se a "gramática universal" do discurso humano que privilegia o universo da imagem simbólica onde se condensam as pulsões, desejos, nostalgias e prospecções de toda a realização humana, individual ou cultural, e onde se situa as próprias produções científicas construídas pelo homem e da civilização.

Neste ponto, é importante que se resgate, com a sociologia das profundezas, a figura de homem como o centro de múltiplas potências mais ou menos contraditórias, ao mesmo tempo bom e mau, anjo e demônio, diurno e noturno, consciente inconsciente, racional e emocional, lógico e intuitivo.

Finalmente, como a epistemologia genética pós-piagetinana tem freqüentemente insistido, o conhecimento humano segue regras e configurações precisas e estruturadas de sentido, carregadas de conteúdos afetivos, representacionais e intencionais.

Numa perspectiva sociopsicogenética, e em termos pós-piagetinos, o desafio das ciências humanas será certamente, nesta passagem de milênio, a construção uma ontologia do imaginário, tomado aqui como lugar do desdobramento da imaginação criadora humana (geradora do pensamento sensório-motor, figurativo ou intuitivo ou lógico).

Para que a Ciência atinja tal grau de maturidade, pesquisadores e investigadores da vida social necessitam reconhecer a importância do simbolismo da vida individual e coletiva na forma como o pensamento humano opera o real.

Deste projeto intelectual, e sua démarche antropológica, o desafio é o de se apontar para as invariantes antropológicos do conhecimento humano" debruçando-se sobre as "obras da cultura" a partir da dinâmica de estrutura do simbolismo que as animam: discursos científicos, obras de arte, ideologias, sistemas políticos, sociais, econômicos, sistemas de pensamento, categorias de entendimento. ${ }^{23}$

\footnotetext{
${ }^{23}$ A propósito ver Figures mhytiques et visages de l'oeuvre, Berg International, Paris, 1979.
} 


\section{BIBLIOGRAFIA}

DURKHEIM, E. "Représentation individuelles et représentations collectives", in: Revue de Métaphysique e de Morale. Paris (1898).

Les formes élémentaires de la vie religieuse. Alcan, Paris, 1912.

\& Mauss, M. "Les formes primitives de classification". In: Année sociologique, VI. Paris, 1901-1902.

DURAND, G. Les structures anthropologiques de l'imaginaire, Dunod, Paris, 1984.

Science de l'homme e tradition, Berg. Internationale, Paris, 1979.

Figures mythiques et visages de l'oeuvre, Berg International, Paris,

1979

FOUCAUL, M. Archéologie du savoir. Paris, Gallimard, 1980

Les mots et les choses. Paris, Gallimard, 1966

GOODY, J. La Raison graphique: la domestication de la pensée sauvage. Minuit, Paris, 1979

La logique de l'écriture: aux origines de la société humaine, Armand Colin, Paris, 1981.

HAVELOCK, E. Aux origines de la civilisation de l'écrite en Occident. Maspero, Paris, 1981.

KUHN, T.S. A estrutura das revoluções científícas. São Paulo, Perspectiva, 1994.

LAFONT, R. Anthropologie de l'écriture. CCI Centre George Pompidou, 1984.

LÉROI-GOURHAN, A. Evolução e Técnicas, vol. I e II, Edições 70, s.d.

La Geste et la Parole, Albin Michel, Paris, 1968.

LÉVY-BRUHL, L. La mentalité primitive. Alcan, Paris, 1925.

LEVI-STRAUSS, C. La pensée sauvage. Plon, Paris, 1962.

PIAGET, J. Estudos Sociológicos. Barcelona, Ariel SA, 1983.

TOURRAINE, A. Crítica da Modernidade, Vozes, Petrópolis, 1995Vozes, Petrópolis, 1995.

VIGOSTKY, L.S. Pensamento e Linguagem, Martins Fontes, SP, 1995.

A formação social da mente. São Paulo, Martins, Fontes, 1994. 